\title{
"A Marginália como imagem transgressiva: ligações entre a página medieval e o graffiti contemporáneo"
}

Tese de Mestrado em Artes Visuais/ Intermédia, apresentada à Escola das Artes da Universidade de Évora, em 2009. Orientação do Professor Escultor Sebastião Resende.

\section{Rita Costa Carvalho}

\section{(2) OpenEdition}

\section{Journals}

Edição electrónica

URL: http://journals.openedition.org/medievalista/489

DOI: 10.4000/medievalista.489

ISSN: 1646-740X

Editora

Instituto de Estudos Medievais - FCSH-UNL

\section{Refêrencia eletrónica}

Rita Costa Carvalho, «"A Marginália como imagem transgressiva: ligações entre a página medieval e o graffiti contemporáneo" », Medievalista [Online], 8 | 2010, posto online no dia 01 dezembro 2010, consultado o 15 setembro 2020. URL : http://journals.openedition.org/medievalista/489

Este documento foi criado de forma automática no dia 15 setembro 2020.

\section{(c) (7) (5)}

Mediavalista está licenciado com uma Licença Creative Commons - Atribuição-NãoComercial 4.0 Internacional. 


\section{"A Marginália como imagem transgressiva: ligações entre a página medieval e o graffiti contemporáneo"}

Tese de Mestrado em Artes Visuais/ Intermédia, apresentada à Escola das Artes da Universidade de Évora, em 2009. Orientação do Professor Escultor Sebastião Resende.

\section{Rita Costa Carvalho}

Gostaria de expressar o meu reconhecimento ao meu orientador, Prof. Escultor Sebastião Resende, pelas contribuições para o tratamento do tema e ainda pelo empenho e generosidade no tempo dispendido em discussões sobre a dissertação.

A minha gratidão vai também para o Prof. Doutor Heitor Alvelos, Prof. Doutora Adelaide Miranda, Inês Carvalho e Prof. Doutora Maria João Gamito pelo encorajamento e aconselhamento em diversas matérias ligadas à marginália.

Finalmente, agradeço à minha familia e aos meus amigos por todo o apoio prestado durante o processo de investigação.

\section{1- A Marginália}

1 A palavra Marginália deriva do termo latino "marginalia" que significa "Coisas escritas na margem" (Faria e Pericão, 1999; Houaiss, 2003). Sendo a génese do termo associada ao manuscrito medievo ${ }^{1}$, as ditas "coisas" existentes na periferia da página podem referir-se a palavras ou a imagens. É Marginália a glosa (texto colocado na periferia da página como explicação ou comentário ao texto principal e central), mas também a pequena anotação ou o diagrama, quando inscritos nos limites da página. O objecto do nosso estudo enquadra-se na Marginália materializada em imagens, ficando excluída a Marginália formada por palavras. 
2 No que se refere à Marginália medieva, existe um variado leque de temas e linguagens visuais, dos quais selecionámos apenas alguns exemplos adequados à nossa reflexão, cujo campo de análise passamos a explicar:

3 A investigação parte da observação de Marginália medieval que despertou o nosso interesse pelas relações que aparentemente estabelece com o texto principal. Como exemplo, encontrámos páginas de missais cujo texto está cercado por imagens que representam macacos, trapezistas ou seres antropomórficos potencialmente satíricos como bispos com pés de bode (cujas expressividade e dinamismo os tornaram foco do nosso entusiasmo). Considerámos, desde logo, intrigante a coabitação dessa Marginália profana e aparentemente provocatória com o texto religioso, especialmente num contexto medievo em que, por um lado, o texto sagrado (cristão) constitui a Lei em grande parte da Europa, e em que, por outro, a imagem ilustrativa (iluminura) se presta ao esclarecimento e exaltação dessa mesma Lei divina. De facto, a Marginália distinguese desta imagem subordinada ao texto que é a iluminura.

4 À partida, o lugar onde a Marginália se inscreve (Margem) sugere-nos uma abertura que torna possível a transgressão ou mesmo subversão do sentido do texto central, neste caso sagrado- que designamos neste trabalho como Texto Oficial, isto é, aquele que, emitido por uma entidade que detém poder, pretende transmitir uma mensagem específica relativa a essa entidade, procurando por esta razão univocidade.

tricámos imagens transgressivas noutras margens que não as do manuscrito medievo (fig.1). Referimo-nos ao graffiti contemporâneo (ou a uma parte do mesmo), manifestação gráfica que parece questionar o Texto Oficial- neste caso, o espaço urbano e suburbano ${ }^{2}$ - à semelhança das imagens encontradas nos fólios medievos.

O graffiti é hoje uma prática omnipresente, envolvendo diferentes tipologias de inscrições realizadas em contextos igualmente distintos. Tendo (re)emergido na PósModernidade enquanto inscrição rudimentar feita em edifícios e transportes públicos, o graffiti foi aumentando o espectro de temas e técnicas, conquistando notoriedade, e, consequentemente, outros lugares de representação. Hoje, para além de constituir uma simples intervenção gráfica nas ruas (uma frase escrita numa parede, uma marca (tag) feita num comboio, um desenho inscrito num muro), o graffiti pode ser objecto de exposição numa galeria de arte, ou ainda aplicação com fins comerciais- em objectos e espaços pertencentes a marcas.

7 Para o nosso estudo convocámos apenas exemplos de graffiti materializado em imagem, dando especial enfoque a imagens aplicadas nas ruas, de forma não autorizada. 
Fig. 1- Nova lorque, 2007

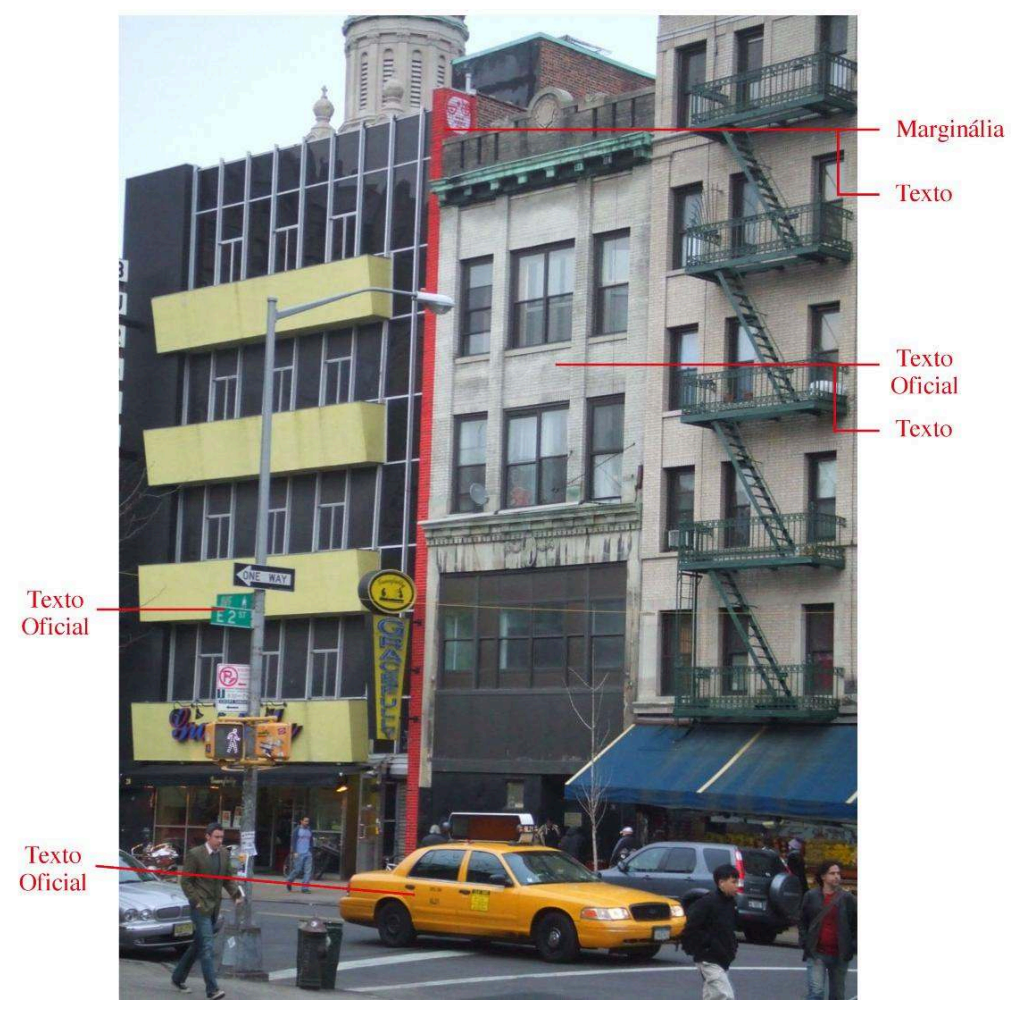

\section{2- Os contextos da Marginália medieval}

8 A Marginália medieval (catalisadora de toda a investigação) levanta várias questões ligadas, nomeadamente ao contexto geral da sua produção e utilização. $O$ breve estudo desenvolvido acerca do cenário sócio-ecónomico e cultural da Europa medieval dos sécs. XIII e XIV (períodos relativos a grande parte dos exemplos seleccionados), fornece-nos indícios sobre a estrutura social da época e suas mutações, mas também o efectivo poder da Igreja (emissora do Texto Oficial) e a sua influência na produção, circulação e leitura dos códices.

9 A estrutura da sociedade medieval surge-nos como um sistema trinitário, altamente hierarquizado, formado pela nobreza, clero e povo, e cuja rigidez seria abalada pela emergência da burguesia (Duby, 1994). Vivia-se dentro das muralhas de uma cidade que oferecia protecção, mas que, simultaneamente, impunha uma forma de vida exclusivamente colectiva. Marginais a este sistema (e vivendo frequentemente fora dos limites da cidade) estavam os hereges, os mendigos, os leprosos e ainda todos aqueles que escolhiam o nomadismo como forma de vida, como os jograis, dançarinos e contorcionistas, entre outros. Estes indivíduos são frequentemente representados nas margens dos manuscritos, levando-nos a constatar a coincidência entre marginalidade social, geográfica e representacional, interessante para a investigação.

10 Ainda relativamente a essa estrutura, é de mencionar o clero como classe detentora de um poder que por vezes se sobrepunha ao régio, e que dominava várias dimensões da vida medieva, entre as quais a escrita (nos mosteiros fundam-se as primeiras escolas e centros de produção de códices- scriptoria). Com efeito, o códice é acolhido no seio do Cristianismo, que o reconhece e utiliza como instrumento de fixação, legitimação e 
difusão da fé. Para além de veículo de transmissão da mensagem cristã, o códice tornase ele mesmo símbolo cristão e afirmação de soberania (Miranda, 2001a).

11 O clero é ainda protagonista de uma reforma (religiosa) conducente a um despojamento que, nomeadamente, se faria sentir na iluminura portuguesa e também na escassez de Marginália nos manuscritos portugueses medievos. Da reforma resulta ainda a emergência das ordens mendicantes cujos exempla, histórias anedóticas contadas como apêndice no fim do sermão, julgamos ter correspondência enquanto tema na Marginália medieva (Randall, 1957).

As trocas e relações comerciais, assim como a criação das universidades são factos que vêm impulsionar a procura de novas obras assim como a criação e circulação de conhecimento. Com efeito, é junto à Universidade de Paris que surgem as primeiras oficinas laicas de produção de códices que rapidamente ultrapassam a produção monacal em número e qualidade (à excepção de Portugal, cuja produção monástica continua a prevalecer sobre a laica até ao séc. XIV, altura na qual a produção diminui, dando início a uma fase de importação de obras produzidas em outros países europeus, como França).

Para além da emergência das oficinas laicas em alguns pontos da Europa, encontramos possíveis condições para a inscrição das imagens profanas marginais na relativa autonomia do iluminador que, a partir do séc. XII trabalha por vezes externamente para scriptoria, estando assim mais protegido da censura clerical. Em relação à organização do seu trabalho, constatamos a existência de alguma liberdade na escolha do modo de representação dos temas, prevalecendo por vezes as suas opções sobre as indicações do seu superior (Alexander, 1992). Essa mesma liberdade poderia explicar em parte a aplicação da provocatória Marginália nos manuscritos. Nascimento $(1999$, p.102) chega a afirmar que o iluminador "não raro, introduz elementos complementares não necessariamente controláveis pelo texto que serve". No entanto, em relação à inscirção da marginália ficamos num plano especulativo, inclusivamente porque a lista dos seus possíveis autores não se limita ao iluminador, incluindo o escriba, o filigranador e mesmo proprietários de códices.

14 Pareceram-nos igualmente relevantes para a investigação as mutações ocorridas na leitura durante o período estudado, dado que, de um acto exclusivo do clero, colectivo e realizado em voz alta (sendo as interpretações textuais extremamente controladas pela Igreja), passa gradualmente a um acto individual e feito em silêncio, estendido agora às classes laicas, nomeadamente a uma burguesia que vem alargar o espectro de obras produzidas, manifestando predilecção por obras profusamente ornamentadas nas margens, como são exemplo alguns saltérios e livros de horas.

Instabilidade e desagregação fazem-se sentir no séc. XIV, que, contrastando com o século anterior, é marcado por fomes, epidemias e ainda revoltas sociais. Peixeiro (1986) relaciona a grave crise sentida nesta época com a profusão de Marginália monstruosa no cod. CXXIV/1-11 ${ }^{3}$ (do qual apresentamos alguns fólios para análise durante a dissertação). Sublinhamos esta acepção de Marginália de Peixeiro, uma vez que acompanha a ideia geral de onde partiu a investigação, isto é, da Marginália como uma reacção de evasão ou de resistência à realidade vivida.

\section{3- Os Lugares da margem}

O aprofundar de questões que se prendem à Marginália implica uma reflexão sobre os lugares que ela ocupa, ou seja, as margens. 
17 A caracterização desses mesmos lugares reveste-se de alguma complexidade pois, se a margem no manuscrito medieval se situa invariavelmente nos limites da página, a margem na cidade contemporânea contempla outros lugares que não os espacialmente liminares.

Partimos de uma definição geográfica que situa a margem num lugar periférico, servindo-nos do mapa-múndi do séc. XIII ${ }^{4}$, representação espacial (embora substancialmente ficcionada) de um lugar. O mapa evidencia um contraste entre o seu centro, locus da Ordem cristã onde está representada Jerusalém, e a sua caótica periferia, lugar do desconhecido e dos medos, onde inclusivamente se inscrevem monstros, figuras que vivem à margem dessa Ordem agostiniana, central e divina.

o observado no mapa-múndi medieval confirma-se no fólio medieval, dado que também neste a margem surge como lugar de alteridade. De facto, é nessa terra de ninguém que se faz representar o outro, expresso em criaturas híbridas, animais obscuros ou marginais da sociedade (nómadas, estrangeiros, etc...).

20 A comparação entre os dois suportes medievos revela um outro traço comum: tal como ocorre na margem do mapa medievo, a Marginália do fólio (inscrita num lugar liberto da formatação existente no resto da página) mostra uma liberdade e dinamismo em nada condizentes com a imutibilidade do seu centro.

21 Para reflexão sobre o lugar onde o graffiti se inscreve e como extensão dessa ideia de Margem como um espaço livre (ou terra de ninguém), apresentámos na dissertação uma fotografia referente a um espaço fora dos limites da cidade contemporânea: uma auto-estrada.

22 Essa auto-estrada parece constituir a antítese de um centro urbano, no sentido em que não se lhe conhece a história e não é habitado a não ser pelos breves segundos de uma passagem. Mais do que uma "no man's land" ou terra de ninguém, este sítio encontra uma caracterização mais precisa no conceito de Não-Lugar de Augé (2007, p.67): “"'Se um lugar se pode definir como identitário, relacional e histórico, um espaço que não pode definir-se nem como identitário, nem como relacional, nem como histórico, definirá um não-lugar."

Contudo, apesar da mencionada auto-estrada excluir uma ocupação permanente e uma dimensão histórica, não é estéril ao nível das significações. Augé sugere que esses espaços "entre" estão mais ou menos preenchidos com informação Oficial (proveniente de uma entidade moral ou instituição), cujo registo será mais ou menos explícito, como são exemplo frases informativo-propagandísticas ou um simples sinal de trânsito.

O Não-Lugar surge-nos ainda como um espaço que se define por uma simultânea carência e excesso: carência de identidade, história e da vivência de uma "sociedade orgânica" (Augé, 2007) e o excesso próprio daquilo que o autor aponta como sendo a era da sobremodernidade ${ }^{5}$. A auto-estrada sugere precisamente a tradução imagética dessa aceleração sobremoderna. Ainda, a combinação dessa velocidade com a ausência de referências históricas parece conferir uma liberdade ou abertura a esse mesmo lugar, que lhe dá um estatuto de objecto provisório e passível de contínuas mutações.

Para além de auto-estradas, estão incluídos no conceito de não-lugar aeroportos, centros comerciais, e, pela ausência de vivência de uma sociedade orgânica, edifícios abandonados e outros espaços vazios. Hoje, esses edifícios abandonados ou vazios não se situam exclusivamente na periferia da cidade ou no exterior da mesma (como na cidade medieva ou mesmo no fólio), encontrando-se agora disseminados numa urbe 
que já não vive à volta de um centro e que tem dificuldades em definir os seus limites. Habitar esse mesmo local, que Peixoto (1998) caracteriza como "inabitável") poderá então passar pela criação de uma extensão gráfica do real e seu respectivo Texto ou ainda de alternativas ao mesmo.

Mas a margem transcende o Não-Lugar: ela também é a abertura criada através da inscrição de um graffiti num Lugar habitado. Ao acolher a Marginália, esse Lugar cria um sub-lugar que, suspendendo as suas funções simbólicas originais, devém Margem, ou seja, locus de inscrição e de exposição de imagens constituintes de discursos paralelos ou mesmo opostos ao Oficial.

\section{4- Caracterização da inscrição marginal} de vista, sendo que alguns se mostraram especialmente relevantes para a investigação É o caso da moralização identificada por Dale (Mellinkoff, 2004), mas também por Randall (1957) e Bakhtin (1968); da função de resistência social apontada por KenaanKedar e Camille (2006); mas também do contributo de Sheridan e Ross (Mellinkoff, 2004) que explica as figuras híbridas marginais como presença residual de uma cultura pagã que o Cristianismo tolera e emprega para conquistar as populações. Ainda sobre figuras pagãs, registámos a teoria de Mattoso (1999) que refere o dragão como uma figura que, desempenhando uma função ornamentativa, evocaria ainda a violência e o poder da Natureza, para sublimação de medos e protecção. Menciona-se ainda a teoria de Schapiro (Camille, 2006) que associa a Marginália a uma espécie de libertação catártica.

31 A marginalidade está na génese do graffitit contemporâneo, dado que este surge precisamente na periferia de Manhattan, Nova Iorque, em bairros caóticos ou em zonas mais desabitadas nos finais dos anos sessenta, sendo inicialmente praticado por jovens de classes e etnias desfavorecidas, e, de certa forma, marginais à sociedade americana. É neste contexto que jovens maioritariamente negros, porto-riquenhos (entre outras etnias), na sua grande maioria menores de idade, invadem as ruas durante a noite, marcando a sua passagem através da inscrição de nomes de código, com uma lata de tinta em spray (aerossol). Estes jovens writers tornar-se-iam os protagonistas de um grande fenómeno, em 1973 descrito como a primeira autêntica cultura juvenil a surgir das ruas desde o tempo do Rock $n^{\prime}$ Roll nos anos cinquenta.

Esse forte entrosamento do indivíduo com a cidade e com a própria vida como ponto importante na produção artística, evoca-nos a Internacional Situacionista (I.S.), 
movimento formado por artistas europeus na década de 50 do séc. XX (entre os quais Guy Debord), cujo projecto ultrapassava o domínio da arte, estendendo-se à própria vida: segundo Debord (1991), a sociedade ("sociedade do espectáculo") encontrava-se num estado de passividade e alienação porque exposta a um contínuo estímulo capitalista. Como forma de combater essa alienação, os situacionistas propunham uma alteração radical na forma do indivíduo viver o quotidiano, o que passaria pela construção de situações possibilitantes de uma fruição mais livre da cidade, como a deriva (dérive), na qual o indivíduo escolheria o seu itinerário (que Debord intitula de psico-geográfico), vagueando pelas ruas e permitindo-se outras percepções e sensações do lugar percorrido. Reconhecemos ainda o encontro entre o graffiti e a I.S. num outro tipo de acção praticada por estes últimos: o desvio (détournement). Esta acção consistia na apropriação e posterior intervenção irónica sobre um objecto (Texto Oficial), alterando-lhe o sentido original. Estes objectos podiam ser um anúncio publicitário, uma banda desenhada, entre outros.

Datam dos anos 80 as primeiras exposições individuais de graffiti. Nessa década, associado à cultura hip hop, o graffiti é omnipresente em Nova Iorque, sendo então apontado pela imprensa como uma prática artística, ainda que polémica. Entretanto, a febre do graffiti estendia-se a uma grande parte do mundo ocidentalizado.

Hoje em dia, o graffiti tem uma forte presença na paisagem urbana. Se as técnicas e mensagens expostas são múltiplas, as motivações também o são.

Um fenómeno que ocorre com o graffiti (tal como com outras formas artísticas marginais) é o de uma absorção do mesmo pelo próprio establishment ao qual inicialmente se opunha. Dada a sua componente criativa e o entrosamento com as camadas jovens, nomeadamente de alguns bairros desfavorecidos de etnias nãodominantes, o graffiti tem vindo a ser integrado no discurso político (e, consequentemente, na comunicação social). Em alguns eventos, o graffiti tem sido citado, quer como parte de uma mensagem de tolerância e integração social, quer como incentivo à criatividade e inovação. Ainda, o graffiti tem vindo a ser adoptado por marcas e respectivos mecanismos publicitários cujo target é a juventude.

Para além do graffiti já absorvido pelo establishment, existem na actualidade muitas outras formas de graffiti protagonizadas, nomeadamente, por artistas ou estudantes de Artes ou Design (Marques [et al], 2000) que encontram nas ruas o suporte ideal para o seu trabalho, como são exemplo a artista Swoon (Garfield, 2007) ou o artista Dan Witz (Schiller, 2007).

37 Provenientes de autores com ou sem formação artística, alguns trabalhos de graffiti assumem hoje uma intenção marcadamente contestatária ou subversiva, que se concretiza em peças extremamente irónicas e que por vezes se oferecem ao público como objectos de provocação ao establishment. Será o caso dos graffitis de Banksy (2006), autor controverso que, de uma forma irónica, torna visíveis algumas questões incómodas ao discurso Oficial.

\section{5- A Marginália como expansão}

No decorrer da investigação, identificámos dois fenómenos nas relações que a Marginália estabelece com o Texto Oficial e que serviram de mote para reflexão. 
Um dos fenómenos confirmados durante o processo de investigação é o de uma expansão nas significações e fruição do Texto Oficial, ocorrendo esta a vários níveis:

Em primeiro lugar, constatámos que ela existe pela simples adição de outra camada de informação (a marginal). Esse alargamento na fruição e interpretação do Texto Oficial não se limita à adição deste segundo elemento, a Marginália. Com efeito, para além de constituir uma nova experiência e conjunto de significações, ela vem introduzir a possibilidade de novas ligações entre Textos. Tratando-se, portanto, de uma ligação hipertextual (Landow, 1995), multiplicam-se as narrativas e os pontos de vista, propondo-se outros itinerários de leituras. São disto exemplo imagens como um graffiti hiperrealista de Dan Witz inscrito num contentor ${ }^{7}$ de lixo e a imagem marginal de um monge aninhado ao canto de um fólio medievo ${ }^{8}$. Apesar de não evidenciarem ligação semântica com os respectivos Textos oficiais (contentor e missal), introduzem expansões nas significações dos respectivos objectos onde se inserem, assim como descentramentos nas leituras (que, em vez de focadas no Texto Oficial, se desviam para a imagem marginal). Essa adição hipertextual de imagens, ideias e narrativas constitui já um prenúncio da subversão do Texto Oficial, uma vez que pluraliza, dinamiza e relativiza uma leitura do Texto Oficial que se pretendia una, sólida e imutável.

A investigação revelou que a expansão operada pela Marginália ocorre igualmente no sentido em que esta faz emergir o invisível. De facto, para além daquilo que é apreendido, utilizado e consumido, a cidade compõe-se de inúmeras camadas de informação (ideias, imagens e narrativas) que estão escondidas, revelando-se pontualmente ao habitante ou transeunte ${ }^{9}$. Por vezes, tomam a forma de um relato de histórias de um armazém ou do passado de uma rua. O graffiti é, no entanto, uma outra forma possível de revelar o invisível ao habitante, intensificando e expandindo o seu entendimento e fruição da cidade. Com efeito, ele mostra uma dimensão escondida dos edifícios e transportes urbanos: a de suporte artístico.

2 Os próprios temas representados participam por vezes nessa revelação, como acontece com o furacão Katrina evocado por Banksy em Nova Orleães, ou com os anónimos habitantes de Nova Iorque homenageados nos graffitis de Swoon. invisível concretiza-se na representação de um outro lado do texto, ou seja, uma espécie de bastidores do acto da cópia e da iluminação do manuscrito, que se fazem representar na margem. Esses bastidores incluem o auto-retrato do iluminador ou do escriba, também existentes nas margens do fólio. A dilatação de significações operada por estas imagens é ainda potenciada pelas ligações hipertextuais já mencionadas.

4 A expansão operada pela imagem marginal reside, em alguns casos, no próprio desenho que a configura. Com efeito, encontrámos imagens que transcendem o registo hermético e identitário próprio da iluminura medieval (Lima, 2007), inscrevendo-se com linhas e formas abertas que fundem figura e fundo, como que desvinculadas da rigidez da sua função representativa.

Assumindo um registo subjectivo, essas formas parecem passear pelos limites do fólio, evocando a frase de Paul Klee: “A drawing is simply a line going for a walk”, percepção para a qual contribui ainda o modo de organização igualmente dinâmico das figuras na margem.

A aparente espontaneidade nesses desenhos denuncia um prazer no acto de inscrição, definindo-o como um exercício de liberdade ou mesmo de libertação, o que evoca a 
interpretação das funções da Marginália por Schapiro (Mellinkoff, 2004), que a entende como uma catarse materializada graficamente. Embora questionando o seu conceito de inscrição marginal como um acto inconsciente, sublinhamos a ideia dessa mesma inscrição enquanto expulsão de algo irracional. De facto, o desenho marginal sugere em alguns casos uma evasão à realidade ou uma libertação de tensões, nomeadamente, as implicadas na tarefa intensiva e monótona da cópia do manuscrito.

Será o caso de uma série de rostos que, num registo caligráfico ${ }^{10}$ evocam o modo de registo do doodling- registo feito frequentemente nas margens de folhas, de forma inconsciente, ou seja, enquanto a atenção está dirigida para outra acção, como falar ao telefone- nomeadamente no que respeita ao seu dinamismo e liberdade (Slobtseva, 2006).

Nessa mesma imagem identifica-se uma outra característica do doodling: a aproximação entre escrita e desenho. Essa relação de intimidade entre texto e imagem marginal sugere que esta, para além de uma expansão do Texto Oficial, ameaça comprometer a sua soberania.

Identificámos um registo semelhante em graffitis que mostram um desenho igualmente livre, espontâneo e inconsequente, expandindo a leitura que fazemos da cidade, como é exemplo um graffiti representativo de uma baleia do artista $\mathrm{Choe}^{11}$.

O incidental graffiti (Alvelos, 2003), registo gerado a partir do aborrecimento ou de uma predisposição para o lúdico, contempla ainda esse desenho que, demonstrando o gozo na simples intervenção, passeia pelas margens, expandindo o hermético Texto Oficial.

51 A Imagem revela-se como um elemento significativo na expansão do Texto oficial, dado que potencia uma multiplicação de significações. Com efeito, se a Imagem vinculada a um texto, como é exemplo a iluminura, é por ele delimitada no que respeita às suas significações, a Imagem marginal vive autónoma na imprevisível polissemia que a define (Barthes, 1995).

A relação de vizinhança entre uma polissémica imagem marginal e um texto oficial que se pretende unívoco pode gerar desconforto. É o que nos sugere o comentário escrito no séc. XII por S. Bernardo (Camille, 2006), o qual expressa o seu desagrado em relação à Marginália monstruosa, manifestando receio de um preterimento do texto litúrgico pela estranha beleza dessas imagens marginais. De facto, S. Bernardo insiste em monstros híbridos, figuras que com a sua "estranha formosura", exerceriam atraç̧ão sobre os homens. Identificamos aqui uma ligação entre o monstro e a problemática da imagem. Por um lado, o monstro é, etimologicamente, aquele que se mostra (Gil, 2006) revelando-se ostensivamente como imagem (fascinante). Por outro lado, o monstro, tal como a imagem, é aquele que, com a sua hibridez, recusa qualquer definição, situandose no plano do inominável (porque polissémico). Portanto, mais do que um receio pela representação do monstro, o testemunho de S. Bernardo sugere-nos um desassossego em relação à força da imagem e à expansão incontrolável das suas significações.

Através do projecto de Januário (2005), que incluiu a aplicação de um graffiti com a imagem \pm e consequente levantamento de leituras por parte do transeunte/ habitante, constatamos que o receio por essa ambiguidade da imagem autónoma é um fenómeno igualmente existente nos dias de hoje. Essa ausência de texto ou de uma legenda que acompanhe a imagem \pm , e a proliferação descontrolada de significações que a mesma implica, desorienta e, por vezes, intimida o observador. De facto, algumas respostas ao inquérito que Januário distribuiu expressam o receio sentido no confronto com a 
imagem \pm . Alguns dos inquiridos associam a imagem a uma seita religiosa, imaginandoa parte de uma campanha para a mesma.

Esse receio medieval e contemporâneo evidencia uma sociedade ocidental identitária $e$ dependente de uma racionalidade discursiva e textual para mediar relações com o real. Neste contexto, a ideia de uma pluralização de significações e de identidades que a imagem faculta aterroriza, levando-nos a evocar as palavras de Michel Serres (Tucherman, 2004): "Fugimos do pensamento da multiplicidade enquanto tal."

\section{6- A Marginália como inversão}

O segundo fenómeno observado na Marginália e orientador da nossa reflexão refere-se a uma inversão ou subversão do Texto Oficial.

Essa inversão marginal pode ocorrer pela simples introdução de ruído entrópico na metrópole, arquétipo da Ordem segundo Rabot ${ }^{12}$. Neste sentido, convocámos a "pichação" (Manco, 2005), graffiti oriundo da cidade S. Paulo que ameaça uma ordem em particular: a ordem do visível.

Por vezes, os temas empregues na Marginália operam essa mesma inversão do Texto oficial.

Com efeito, recolhemos durante a investigação Marginália constituinte de um universo oposto ao do Texto Oficial, formando uma espécie de anti-ilustração daquilo que ele significa. De facto, existem inúmeras imagens de um mundo às avessas onde as hierarquias sociais e seus respectivos estatutos se invertem. Assim, encontramos no graffiti a subversão da monarquia britânica protagonizada por uma Raínha Vitória que, com pernas desnudadas e ceptro em punho, assassina uma outra mulher ${ }^{13}$. 0 mesmo tom subversivo é sugerido na imagem medieva de um bispo que, com corpo de animal, se apresenta como escravo dos seus impulsos, voltando costas ao texto sagrado ${ }^{14}$.

59 A iconografia medieva, tal como o graffiti, cumpre um papel nessa provocação ao poder, revelando imagens profanas que propõem essa inversão do mundo oficial cristão. Assim, encontramos nas margens de diversos manuscritos representações de nudez e do acto sexual (ligado ao culpabilizado acto sexual, está a concepção neoplatónica de corpo, que o entende como uma forma de humilhação e de prisão para a alma) ou imagens de animais que têm conotações negativas associadas a falhas humanas como o macaco ou o bode.

Alguns modos operatórios da Marginália constituem igualmente factores de inversão do Texto Oficial. Um deles é a paródia (Hutcheon, 1989) presente em fólios cuja margem se apropria de um elemento do Texto Oficial, desviando o seu sentido (a paródia consiste precisamente na convocação de um objecto e intervenção sobre o mesmo, da qual resulta um segundo objecto, frequentemente com um sentido oposto ao do original). Como exemplo, expomos na dissertação um fólio ${ }^{15} \mathrm{em}$ cuja margem um galo parodia o cântico retratado na iluminura central do mesmo fólio, satirizando o clero, segundo Randall (1957).

61 Peças como um add-on (graffiti paródico executado sobre um objecto já existente, alterando-lhe o sentido) de Dr Hoffman, ou ainda as intervenções de Banksy no Muro da Vergonha, na Palestina, constituem paródias que evocam, inclusivamente, a ironia dos desvios ou détournements dos situacionistas. Em alguns desses graffitis paródicos, o 
humor está presente como mecanismo transgressivo, tal como acontece em alguma Marginália medieva.

De facto, a apresentação de uma inversão satirizante do instituído (como o bispo híbrido e outros elementos que habitam a drôlerie ${ }^{16}$ ), é parte integrante do humor na Idade Média, estando inclusivamente presente em representações teatrais e espectáculos carnavalescos nos quais as cidades suspendem a ordem oficial (subvertendo hierarquias sociais numa festa partilhada por plebeus mascarados de senhor feudal, frades envergando vestimentas de rei, mas também bispos usando vestes de plebeu), abrindo um espaço e tempo intersticial que, simultaneamente celebra e escarnece. Segundo Bakhtin (1968) essas imagens terão migrando dessas manifestações para as margens do manuscrito.

\section{7- A ambiguidade da Marginália}

No final desta investigação concluímos que toda esta subversão marginal se reveste de muita ambiguidade, fenómeno para o qual encontramos várias explicações.

Em primeiro lugar, a ideia inicial de subversão subentendia uma oposição marcada entre Texto Oficial e Marginália, oposição essa que viria a esbater-se ao longo da investigação. Para isso contribuiu a constatação de que a justaposição do sagrado e do profano ocorria, na Idade Média, noutras formas de expressão para além do códice, como é exemplo o teatro, ou mesmo festas profanas que ocorriam em simultâneo com festas religiosas, indiciando, assim, uma prática sistemática dessa mesma coabitação. Vimos ainda o contraste entre Marginália profana e texto sagrado relativizado pelo facto de alguns monstros e criaturas hibridas integrarem o próprio texto biblico (Texto Oficial), como é o caso do Livro do Apocalipse de João Evangelista. Neste texto, os monstros abandonam as margens, migrando para o Texto Oficial, onde partilham o espaço narrativo com figuras sagradas. Essa mesma fusão entre marginal e oficial acontece com o graffiti, que, como mencionado, tem sido adoptado pelo establishment, nomeadamente pelas marcas que o citam como estratégia publicitária de aproximação a um público jovem.

Em segundo lugar, conclui-se que o facto do marginal no mundo cristão medievo (como o mendigo, o leproso, o nómada, o monstro, e mesmo o animal) se inscrever, quase sem excepção, na margem, confere a esta última um estatuto de certo modo conservador.

Portanto, a ambiguidade na inversão existe numa margem que por um lado, constitui o lugar de um mundo às avessas oposto ao Texto Oficial, e por outro, uma espécie de 'jardim zoológico' da página, onde, numa liberdade controlada, o Outro ocupa o seu devido lugar. E, de facto, a margem e o marginal convêm ao centro e ao Texto Oficial. Como Gil (2006) afirma, a apresentação do Outro, do monstro, ajuda a definir os limites do humano, consolidando a sua identidade (em vez de apenas a pôr em causa, como julgávamos no início da investigação).

67 A mesma institucionalização do marginal ocorre no Carnaval, celebração presumivelmente geradora de Marginália medieva. Nesta festa profana opera-se uma suspensão da Ordem Oficial e uma inversão das hierarquias da sociedade, incluindo uma satirização das suas classes e seus costumes. São expressões de uma transgressão. No entanto, trata-se de uma transgressão autorizada, com dia e hora marcada.

o próprio facto da margem ser um lugar menor de representação sugere que a imagem marginal gravita entre a responsabilidade sígnica de veicular mensagem e um simultâneo alheamento da significação. Esta ambivalência da Marginália (à qual se 
junta a simples polissemia da imagem) surge-nos como propícia a algum descomprometimento no que respeita a uma inversão do Texto Oficial.

Durante esta investigação abordámos diferentes casos de Marginália que transcendem o domínio do Texto Oficial com intensidades igualmente distintas. No entanto, todas elas indiciam quase-revoluções que se diluem na ambiguidade que as caracteriza, mas que marcam um acto de libertação e de prazer.

\section{BIBLIOGRAFIA}

ALEXANDER, Jonathan J.G. - Medieval Illuminators and Their Methods of Work. New Haven: Yale University Press, 1992. 214 p. ISBN 0-300-06073-4

ALVELOS, Heitor - The fabrication of authenticity- graffiti beyond subculture. Londres: The Royal College of Art. Communication Art and Design, 2003. 461 p. Tese de doutoramento. (04.09.07)

AUGÉ, Marc- Não-lugares: Introdução a uma Antropologia da Sobremodernidade. Lisboa: Editora 90º, 2007. 101 p. ISBN 972-8964-02-1.

BAKHTIN, Mikhail - Rabelais and his world. Cambridge: MIT, 1968. 484 p.

BANKSY- Wall and Piece. Londres: Century, 2006. 240 p. ISBN 1-8441-3787-2.

BARTHES, Roland - Image, Music, Text. Londres: Fontana Press, 1995.

CAMILLE, Michael - Image on the edge: The Margins of Medieval Art. Londres: Reaktion books, 2006. 176 p. ISBN 0-948462-28-0.

DEBORD, Guy- A Sociedade do Espectáculo. Lisboa: Mobilis in mobile, 1991. 174 p. ISBN 972-716-002-6.

DUBY, Georges - As três ordens- Ou o imaginário do feudalismo. Lisboa: Editorial Estampa, 1994. 383 p. ISBN 972-33-0992-0.

FARIA, M. Isabel, PERICÃO, Maria da Graça- Novo dicionário do livro- da escrita ao multimédia. Lisboa: Círculo de Leitores, 1999. 631 p. ISBN 972-42-1985-2.

FOUCHÉ, Pascal, PÉCHOIN, Daniel, SCHUWER, Philippe- Dictionnaire encyclopédique du Livre. Vol.1. Tours: Éditions du Cercle de la Librairie, 2002. 897 [2] p. ISBN 2-7654-0841-6.

GARFIELD, Joey, ROBERTS, Shawn - The Run Up . Nova Iorque: FIFTY24SF, Upper Playground, 2006. 1 VÍDEO em DVD.

GEREMEK, Bronislaw- The margins of society in late medieval Paris. Nova Iorque: Cambridge University Press, 2006. [11] 319 p. ISBN 0-521-02612-2-3.

GIL, José - Monstros. Lisboa: Relógio d’Água, 2006. 161 p. ISBN 972-708-890-2.

HOUAISS, António- Dicionário Houaiss da Língua Portuguesa. Lisboa: Temas \& Debates, 2003. 2922 p. ISBN 9788573023831.

HUTCHEON, Linda - Uma teoria da Paródia. Lisboa: Edições 70, 1989. 165 p. 
JANUÁRIO, Miguel- Mais ou menos. Porto: Faculdade de Belas Artes da Universidade do Porto, 2005. 31 p. Dissertação de Licenciatura.

LANDOW, George P. - Hipertexto: La convergencia de la teoría crítica contemporânea y la tecnología. Barcelona: Ediciones Paidós, 1995. ISBN 84-493-0186-6, 284 pp.

LIMA, Luís - O desenho como substituto do objecto: descrição científica nas imagens do desenho de materiais arqueológicos. Porto: Faculdade de Belas Artes da Universidade do Porto, 2007. 206 p. Tese de mestrado.

LYNCH, Kewin- A imagem da cidade. Lisboa: Edições 70, 1996. 208 p. ISBN 972-44-0379-3.

MANGUEL, Alberto - Uma História da Leitura. Lisboa: Editorial Presença, 1999. 366 p. ISBN 9789722323390 .

MARQUES, Filomena, ALMEIDA, Rosa, ANTUNES, Pedro - Traços falantes (A cultura dos jovens graffiters). In PAIS, José- Traços e riscos de vida: Uma abordagem qualitativa a modos de vida juvenis. Porto: Âmbar, 2000. ISBN 972-43-0331-4. p. 175-208.

MATTOSO, José- A Iluminura: o Visível e o Invisível. In MIRANDA, Adelaide- A iluminura em Portugal: identidade e influências (do séc. X ao XVI). Lisboa: Biblioteca Nacional, 1999. ISBN 972-565-266-5. p. 25-38.

MELLINKOFF, Ruth- Averting Demons: The Protective power of medieval motifs and themes. Volume1: text. Los Angeles: Mellinkoff Publications, 2004. 196 p. ISBN 0-9748019-0-9.

MIRANDA, Maria Adelaide- Do texto para as margens: O Sagrado e o Profano na Iluminura Medieval. Margens e Confluências. Guimarães: Escola Superior Artística do Porto- Extensão Guimarães. nำ 2 (2001b) p. 55- 75.

MIRANDA, Maria Adelaide- A iluminura no Portugal medieval. Coimbra: Câmara Municipal, INATEL, ADDAC, 2001a. 24 p . ISBN 972-96970-2-7.

NASCIMENTO, Aires A.- Scriptorium medieval, instituição matriz do livro ocidental. In MIRANDA, Maria Adelaide- A iluminura em Portugal: identidade e influências (do séc. X ao XVI). Lisboa: Biblioteca Nacional, 1999. ISBN 972-565-266-5. p. 51-109.

PEIXEIRO, Horácio - Missais iluminados dos sécs. XIV e XV. Contribuição para o estudo da iluminura em Portugal. Lisboa: Universidade Nova- Faculdade de Ciências Sociais e Humanas, 1986. 572 p. Tese de mestrado.

PEIXOTO, Nelson Brissac - Paisagens Urbanas. São Paulo: Senac, 1998. 350 p. ISBN 85-85578-92-0. RANDALL, Lilian - Exempla as a Source of Gothic Marginal Illumination. The Art Bulletin. 39: 2 (1957) 97-107.

http://links.jstor.org/sici? sici=00043079\%28195706\%2939\%3A2\%3C97\%3AEAASOG\%3E2.0.CO\%3B2-\%23 (03 .04. 2008)

RENESSE, Reid Van- Dithers. Nova Iorque: FIFTY24SF, Upper Playground, 2004. 1 VÍDEO em DVD. SCHILLER, Marc; SCHILLER, Sara- [Entrevista a Dan Witz, 2007].

http://www.danwitzstreetart.com/essays.html (02-10-2007).

SLOBTSEVA, Yelena - Drawing in the margins. Bowling Green: Graduate College of Bowling Green State University, 2006. 56 p. Tese de mestrado.

TUCHERMAN, Ieda - Breve história do corpo e de seus monstros. Lisboa: Nova Vega, 2004. 199 p. ISBN 972-699-577-9. 
VERGINE, Lea- Art on the Cutting Edge: A Guide to Contemporary Movements. Skyra, 2001. 303 p. ISBN 88-8118-739-6.

\section{NOTAS}

1. Curiosamente, a difusão da palavra "margem" está intimamente ligada à escrita, facto que Miranda (2001b, p. 71) referencia: "O uso do nome margem, do latim margo que significa limite, cercadura ou fronteira, não se divulgou senão com a propagação da escrita. Desde que o fluxo da palavra se tornou matriz de signos visuais, ela tem lugar não somente para anotações mas igualmente para o desacordo e as confrontações (...)."

2. Apoiados na Semiótica, e seguindo autores como Lynch (1996) e Barthes (1995), entendemos a cidade, na nossa investigação, como suporte de textos passíveis de leituras e percepções.

3. Missal. Sécs. XIV-XV; Biblioteca Pública e Arquivo Distrital de Évora, Évora.

4. Mapa-múndi. Saltério, c. 1260. British Library, Londres. Ms 28681 fl. 9r.; (Camille, 2006, p. 15).

5. Sobremodernidade é o termo que Augé (2007) encontra para definir a contemporaneidade. Esse conceito contempla três figuras do excesso, sendo a primeira o Tempo, associado a uma superabundância de acontecimentos. A segunda figura de excesso é o Espaço, ligado à multiplicidade e superabundância de lugares e, finalmente, o Ego, associado a uma individualização de referências, consequência de um enfraquecimento de referências colectivas.

6. Neste trabalho cingimo-nos ao graffiti contemporâneo, cuja génese situamos na cidade de Nova Iorque nos finais dos anos 60. No entanto, a história desta prática é bastante mais longa, remontando à Pré-História.

7. Humming Birds. Nova Iorque, 2000; http://www.danwitzstreetart.com/birds2000_2.html

8. Monge aninhado. Missal. Sécs. XIV-XV. Biblioteca Pública e Arquivo Distrital de Évora, Évora. Cod. CXXIV/1-11, fl. $213 \mathrm{r}$

9. Possivelmente, e assumindo uma perspectiva debordiana (Debord, 1991), muitas dessas informações escondidas só se tornam acessíveis se provocadas situações que exigem, nomeadamente, alguma disponibilidade e atenção do habitante/transeunte.

10. Doodling na margem. Speculum Historiale. Sécs. XIV-XV. Biblioteca Nacional, Lisboa. Il.125, fl 36. (pormenor da margem de cabeça)

11. Whale, 2004; (Renesse, 2004)

12. Proferido por Jean-Martin Rabot em "Figuras da monstruosidade na pós-modernidade." durante a CONFERÊNCIA INTERNACIONAL IMAGEM E PENSAMENTO. Lisboa: Centro de Comunicações e Linguagens, 2007.

13. Banksy. Rainha Vitória. Londres. s/d.

14. Bispo híbrido. Saltério. Séc. XIV. Biblioteca Pública Municipal do Porto, Porto. Ms. 623, fl.35 r

15. Galo parodiando cântico. Saltério. Colecção de C.W. Dyson Perrins, Malvern. Ms. 11, fl. 146 v.

16. Cena de fantasia que decora a margem de um manuscrito sem remeter directamente para o texto. Músicos, acrobatas, pessoas mascaradas de animais ou outras imagens de um "mundo às avessas", as drôleries constituem imagens híbridas ou cenas profanas, por vezes retiradas de fábulas que, sem ligação com o conteúdo do texto, animam as margens de manuscritos essencialmente ingleses, flamencos ou do norte de França, entre 1250 e 1350 . Libertado da função identitária do desenho, este sistema decorativo funciona como uma antítese do real. (Fouché, 2002) 


\section{RESUMOS}

Propõe-se uma reflexão sobre imagens que habitam a margem enquanto lugar menor ou secundário de representação.

Este trabalho parte de exemplos encontrados em manuscritos medievais e em graffitis contemporâneos e centra-se nas relações que estas imagens marginais (marginália) estabelecem com o texto central e oficial, tratando-se do texto escrito medievo ou da própria cidade contemporânea.

Consideramos que a marginália tende a transgredir esse texto oficial, questionando a sua autoridade e imutabilidade através de uma expansão ou mesmo inversão das suas significações. Nestes fenómenos, a paródia e o humor desempenham um papel relevante.

No entanto, a transgressividade da marginália surge como ambígua, facto decorrente da indefinição própria da imagem e da margem onde se inscreve.

\section{AUTOR}

\section{RITA COSTA CARVALHO}

ESEIG, Instituto Politécnico do Porto; Membro do IEM, Faculdade de Ciências Sociais e Humanas, Universidade Nova de Lisboa.

ritacarvalho@eu.ipp.pt 